Logos Universality Mentality Education Novelty, Section:

\title{
LAW
}

ISSN: $2284-5968$ (print), ISSN: $2284-5968$ (electronic)

Covered in: CEEOL, Index Copernicus, Ideas RePeC, EconPapers, Socionet

\section{THE END BANKING SECRECY IN POST- CRISIS ECONOMICS- FIRST STEP. COTY GERMANY AND HSBC SWISS CASES}

\author{
Carmen Adriana GHEORGHE \\ Doi: http://dx.doi.org/10.18662/lumenlaw.2015.0401.04 \\ Logos Universality Mentality Education Novelty, Section: LAW, \\ 2015, Volume IV, Issue 1, pp: 31-39 \\ Published by: \\ Lumen Publishing House \\ On behalf of: \\ Lumen Research Center in Social and Humanistic Sciences
}




\title{
The End Banking Secrecy in Post- Crisis Economics- First Step. Coty Germany and HSBC Swiss Cases
}

\section{Carmen Adriana GHEORGHE ${ }^{1}$}

\begin{abstract}
Inequality, distribution and growth are important topics in modern post-crisis economics and their interconnections are a favorite subject of economists and international and national institutions. There is strong evidence also that the end of banking secrecy wasn't a real priority for authorities.

On the other hand, unfairness generates economic and political instability that reduces investment and therefore growth. Economic contrast impedes the social consensus necessary to absorb shocks and sustain growth. In this context, what positions should the effects of money laundering and tax evasion, as a result of banking secrecy, occupy? What is the reason for not including banking secrecy among the causes for instability, inequity and, consequently, crisis?

Two recent cases have prompted the adoption of measures on banking secrecy in the E.U. - the Coty dispute between Germany and a German bank (more specifically, the interpretation forwarded by CJUE) and the HSBC Swiss bank secret accounts scandal (respectively, the deal on bank accounts between E.U. institutions and Swiss banks).

Currently, the Romanian economy is characterized by macroeconomic balance and microeconomic tensions - the GDP distribution in economy is inadequate. The disciplined (individuals and legal entities who comply with the law) are tense, the reason being that they do not experience economic growth. Many distribution added value channels are clogged by the indiscipline of other individuals and legal entities. The undisciplined are relaxed, because they acquire and unreasonably large part of the added value in the economy.
\end{abstract}

Keywords: bank secret, CJEU, right of information, bank data exchange agreements, risk.

1 Ph.D, Transilvania University Brasov, Faculty of Law, Romania, carmenghe2003@yahoo.com. 


\section{Introducere}

Intre provocările pe care actualitatea economică, socială şi politică le afişează şi pe care contemporaneitatea le cere a fi soluționate, noțiunea de secret bancar îşi găseşte un loc oarecare şi nu unul principal în contextul actual. Oarecare- deoarece nu are cum să reprezinte o soluție miraculoasă pentru dificultățile actuale din toate planurile existențial-financiare şi nici un instrument în lupta contra fraudei fiscale, aşa cum s-ar dori. Deşi acest termen, secretul bancar, sună miraculous, în ceea ce priveşte desecretizarea sau sfârşitutul său nu mai încape nici o discuție. $\mathrm{O}$ noțiune atât de versatilă nici nu avea cum să fie îngrădită în vreun fel decât, eventual, prin concepte ca morală, etică, responsabilitate socială fiindcă, în speranța că vom putea face simplu, direct distincția între ce poate spune banca şi ce intră sub incidenta secretului, s-ar putea să aşteptăm illo tempore.

Următoarele aspecte definesc prezentul european:

- criza şi post criza cu nevoia de lichidităţi

- frauda fiscală uriaşă care generează inegalitate şi distribuție dezechilibrată

- reforma bancară bazată pe supraveghere

- interesul privat bazat şi pe instrumentul său- secretul bancar- versus interesul public

Acutizarea şi chiar generalizarea unor situaţii de eludare a normelor financiar-fiscale şi bancare au determinat declanşarea unor dezbateri care încep să se concretizeze la nivelul U.E. Astfel, printre primele măsuri concrete pe care organismele europene le-au impus în 2013 se numără modificarea prevederilor în materie de dobânzi ale economiilor pentru eliminarea riscului de evaziune fiscală. Este vorba despre schimbul automat de informații între două state membre privind dobânzile pe economii plătite persoanelor care nu locuiesc în statul unde a fost deschis contul bancar.

\section{Noțiunea de secret bancar}

\subsection{Reglementări interne, europene, internationale}

Se vorbeşte în legislație despre secret profesional, secret comercial, secret bancar. Care sunt corelațiile pe care le putem stabili între aceste noțiuni? Este clar că, atât secretul comercial, cât şi cel bancar, fac parte din categoria secretului profesional. La fel cum este indubitabil că secretul bancar aparține categoriei secretului comercial. 
O scurtă privire aruncată asupra principalilor autori din domeniul dreptului bancar face dovada că nici doctrina nu stă mai bine la capitolul de analiză a principiilor secretului bancar în calitate de instituţie juridică importantă [a se vedea Postolache, R. sau Săuleaanu, L., Smarandache, L., Dodocioiu, A.] Nu numai doctrina uită de secretul bancar, ci şi dezbaterile anuale care au ca rezultat volume ale conferințelor internaţionale de specialitate [de exemplu, Tendinte actuale în domeniul financiar bancar în legislatia națională, europeană și internaţională/National, European and International Legal Developments in Financial and Banking Field].

In ceea ce priveşte terminologia sub care legiuitorul obligă la respectarea secretului bancar acesta vorbeşte de "păstrarea secretului" şi mai puțin de obligația de confidențialitate şi de cea de neuz...UNDE? Astfel, în continutul art. 111 alin. 1 din O.U.G. nr.99/2006 se face vorbire de obiectul secretului bancar şi de obiectul obligației de confidențialitate, iar în art.112 alin.2 - de obligația complementară de neuz: "persoanele care iau cunoştință .de informațiile care se bucură de beneficial confidentialitătii nu au dreptul de a folosi sau dezvălui...fapte sau date.”[Buciu, I.C., p.229 citând pe Turcu.I, Drept bancar, Lumina Lex, Bucureşt, 1999, p.275]

Astfel, Constituția României, în art.26 privind dreptul la viață privată, Legea nr. 312/2004 privind Statutul Băncii Naţionale a României, Legea nr. 656/2002 pentru prevenirea şi sancţionarea spălării banilor, precum şi pentru instituirea unor măsuri de prevenire şi combatere a finanţării terorismului, O.G. nr. 92/2003 privind Codul de procedură fiscală, Legea nr.27/2015 privind Noul cod de procedură fiscală, O.U.G. nr.99/2006 privind instituțiile de credit şi adecvarea capitalului, în art.111-119, Legea nr. 544/2001 privind liberul acces la informațiile de interes public, Legea nr.182/2002 privind protecția informației clasificate reglementează în mod direct sau indirect aspecte legale privind secretul bancar.

Uniunea Europeană reglementează aspecte legate de secretul bancar în acte normative cum ar fi: Directiva 2013/36/UE cu privire la accesul la activitatea instituțiilor de credit şi supravegherea prudențială a instituțiilor de credit şi a firmelor de investiții, în art.4 denumit "Secretul profesional", sau în Directiva 2004/48/CE privind respectarea drepturilor de proprietate intelectuală, în timp ce pe plan internațional putem face referire la Standardul schimbului automat de informații în interes fiscal privind date financiare, propus de O.E.C.D.

Odată cu integrarea în structurile europene, România aplică, în activitatea bancară, prevederile O.U.G. nr. 99/2006. Potrivit dispozițiilor art. 
111 alin. (1), obiectul secretului bancar vizează „toate faptele, datele şi informațiile referitoare la activitatea desfăşurată, precum şi orice fapt, dată sau informație, aflate la dispoziția instituției de credit care privesc persoana, proprietatea, activitatea, afacerea, relaţiile personale sau de afaceri ale clienților- solduri, rulaje, operațiuni derulate, la serviciile prestate sau la contractele încheiate cu clienții”'.

Este vorba, deci, de două categorii care alcătuiesc obiectul secretului bancar: fapte, date şi informații care se referă la activitatea clientului; fapt, dată, informație aflată la instituția de credit cu privire la: solduri, rulaje, operațiuni derulate, servicii prestate şi contracte încheiate.

Obiectul secretului bancar se aplică cu privire la persoana, proprietatea, activitatea, afacerea şi relaţiile personale sau de afaceri ale clientului băncii. Client al unei bănci este orice persoană care beneficiază de serviciile acesteia, între el şi bancă desfăşurându-se o tranzacție care este obiectul obligației de confidențialitate

$\mathrm{Cu}$ privire la obligația de păstrare a secretului bancar aceasta revine persoanelor care iau cunoştinţă de informațiile ce se bucură de beneficiul confidenţialităţii. Acestea „nu au dreptul de a folosi sau de a dezvălui nici în timpul activității şi nici după încetarea acesteia, fapte sau date care, dacă ar deveni publice, ar dăuna intereselor ori prestigiului unei instituţii de credit sau ale unui client al acesteia”. Prin urmare, legea interzice în mod expres personalului băncii să divulge sau să uzeze, în folos personal, de datele pe care le deține, obligațiile fiind impuse de lege atât în timpul activităţii, cât şi după încetarea acesteia.

Ca excepție, obligația de păstrare a secretului profesional în domeniul bancar nu poate fi opusă unei autorități competente în exercitarea atribuțiilor de supraveghere. Prin derogare de la principiul confidențialității informațiilor clienților, legislația bancară reglementează condițiile stricte în care instituțiile de credit supuse legii române pot decide, în cazuri justificate, furnizarea de informații, precum şi cazuri în care acestea sunt obligate să furnizeze informații de natura secretului bancar.

\subsection{Subiectele obligatiei de păstrare a secretului bancar}

Revine băncii obligația de păstrare a secretului bancar şi de neuz a informației în raport cu clientul său. Debitoare a obligației este banca faţă de clientul său, creditor[Silberstein,I., Bercea, L.].

$\mathrm{Cu}$ privire la persoanele care au de îndeplinit obligația este vorba de următoarele categorii: 
- conducătorii, administratorii şi auditorii, respectiv a celor cu atribuții în conducerea, administrarea şi controlul gestiunii băncii

- salariații băncii

\subsection{Temeiul legal al obligației de păstrare a secretului bancar}

Temeiul legal privind respectarea obligației de păstrare a secretului bancar este reprezentat fie de lege, aşa cum s-a aratat mai sus, fie de contractul încheiat între bancă şi client.

\subsection{Conținutul obligației de păstrare a secretului bancar}

Obligația de confidențialitate presupune obligația de neuz a faptelor, informațiilor, datelor. Mai precis, băncii îi revine obligaţia de păstrare a confidențialității asupra detaliilor referitoare la conturile clienților sau a altor aspecte privind relația clienților cu banca, pe de o parte. Pe de altă parte, banca este obligată la păstrarea secretului asupra deciziilor şi operaţiunilor băncii, datorită faptului că accesul la astfel de informații ar putea acorda firmei concurente un avantaj, pe baze neloiale, astfel fiind încălcată libertatea de concurență.

Principalele implicații directe ale încălcării acestei obligații sunt reflectatate în materie comercială în ceea ce priveşte concurența neloială, iar în materie penală în ceea ce priveşte spălarea banilor, frauda fiscală, finanțarea terorismului [Jurj-Tudoran, R.Saguna, D.D.].

\section{Comisia Europeană şi secretul bancar}

Conjunctura actuală impune necesitatea ridicării secretului bancar, instituție îndrăgită timp de mulți ani în Belgia (aceasta a renunțat la el între timp) şi apărat de Austria şi Luxembourg. Austria negociază pentru ca ridicarea secretului bancar să nu-i vizeze pe cetăţenii austrieci.

Comisia Europeana a primit un mandat pentru renegocierea diferitelor acorduri fiscale cu state din afara U.E., respectiv cu Elveția, Andorra, Monaco şi Lichtenstein.

De asemenea, peste 65 de state, inclusiv România, s-au angajat să susţină schimbul reciproc de informatii colectate de la instituțiile financiare privind conturile deținute de persoane fizice şi juridice. Numărul statelor semnatare se aşteaptă să crească substanțial (în octombrie 2014 a avut loc la Berlin Forumul Global al Transparenței şi Schimbului de Informații, cu peste 120 de jurisdicții participante).

\subsection{Reglementări interne ale instituțiilor europene}


În Anexa la Decizia Băncii Centrale Europene- BCE/ECB din 17 septembrie 2014 privind punerea în aplicare a separării dintre funcțiile de politică monetară şi de supraveghere ale Băncii Centrale Europene (BCE/2014/39) (2014/723/UE s-au instituit cinci clasificări ale categoriilor de secret bancar. Astfel, secretul poate fi încadrat între ECB-SECRET, la care accesul în cadrul B.C.E. este limitat strict pe baza principiului necesităţii de a cunoaşte, fiind aprobat de un cadru de conducere superior al B.C.E. din departamentul inițiator sau la un nivel superior, până la ECB-PUBLIC, respectiv secretul care este autorizat să fie pus la dispoziția publicului larg.

\section{Cazul Coty Germania şi secretul bancar}

C.J.U.E. a dat publicității, în 16 iulie 2015, hotărârea pronunțată în cauza C-580/13, Coty Germany, cu privire la proprietate intelectuală şi industrială, vânzare de mărfuri contrafăcute, dreptul la informare în cadrul unei acțiuni privind o atingere adusă unui drept de proprietate intelectuală, reglementare a unui stat membru care autorizează instituțiile bancare să refuze să răspundă în mod favorabil la o solicitare privind furnizarea de informații referitoare la un cont bancar (secret bancar). Cererea a fost formulată în cadrul unui litigiu între Coty Germany $\mathrm{GmbH}$, societate titulară a unor drepturi de proprietate intelectuală, pe de o parte, şi o instituție bancară, Stadtsparkasse Magdeburg, pe de altă parte, în legătură cu refuzul acesteia din urmă de a furniza Coty Germany informații referitoare la un cont bancar. Directiva 2004/48 art.8- alin. (1) şi (2) se aplică fără a aduce atingere altor acte cu putere de lege şi norme administrative care:

(a) acordă titularului dreptul de a primi informații mai extinse;

(b) reglementează utilizarea în cauzele civile sau penale a informațiilor comunicate în conformitate cu prezentul articol;

(c) reglementează răspunderea pentru abuzul de drept la informare;

(d) dau posibilitatea să se refuze furnizarea de informații care ar constrânge persoana menționată la alineatul (1) să admită propria sa participare sau cea a rudelor sale apropiate la încălcarea unui drept de proprietate intelectuală sau

(e) reglementează protecția confidențialităţii surselor de informare sau prelucrarea datelor cu caracter personal."

Curtea a statuat că articolul 8 alineatul (3) litera (e) din Directiva 2004/48/CE a Parlamentului European şi a Consiliului din 29 aprilie 2004 privind respectarea drepturilor de proprietate intelectuală trebuie interpretat în sensul că se opune unei dispoziţii naţionale precum cea în discuție în 
litigiul principal, care autorizează, în mod nelimitat şi necondiționat, o instituție bancară să invoce secretul bancar pentru a refuza să furnizeze, în cadrul articolului 8 alineatul (1) litera (c) din această directivă, informaţii cu privire la numele şi la adresa titularului unui cont.

\section{Cazul Sweesleaks/HSBC Elveția}

Lupta autorităţilor interne ale statelor membre U.E. cu probleme cum ar fi evaziunea fiscală sau finanțarea terorismului solicită o viziune europeană unitară.

Elveția, unul dintre cele mai importante centre financiare off-shore din lume, care gestionează aproape 2.000 de miliarde de dolari, a anunțat, la jumătatea lunii martie 2015 că se va conforma la Standardele Organizației pentru Cooperare şi Dezvoltare Economică (O.E.C.D.) privind Secretul Bancar. Cu toate acestea, autoritățile elvețiene au precizat că acceptarea standardelor O.E.C.D. nu schimbă, în fond, secretul bancar ce se află în vigoare în cadrul confederaţiei. "Elveția păstrează secretul bancar şi refuză transmiterea integrală automată a datelor", a avertizat guvernul, adăugând că "sfera privată a clienților este în continuare protejată de solicitările externe nejustificate". Totuşi, Elveția a încheiat Tratatul cu S.U.A. pentru asistență reciprocă în problemele de luptă împotriva criminalității, intrat în vigoare în ianuarie 1977, care, coroborat cu dispozițiile art.3321 din Codul penal elvețian constituie temeiul legal pentru comunicarea de informații solicitate băncilor elvețiene [Aubert, M.

În urma acuzațiilor aduse băncii HSBC (de exemplu, a alocat milioane de dolari pentru Libyan Investment Authority, controlată de Colonelul Muammar Gaddafi; după asasinarea acestuia, a refuzat să dea informații despre fonduri, invocând obligația de confidențialitate. În 2014 a inchis North London Central Mosque's care avea drept clienți anumite grupări musulmane; sursele spun că filiala a fost închisă deoarece aceste grupări au donat bani către Statul Palestina, în războiul dintre Israel-Gaza ş.a), statele membre vor primi, anual, numele, adresele, datele de identificare fiscală şi datele de naştere ale persoanelor cu conturi în Elveția, precum şi alte informaţii despre situaţia lor financiară.

\section{Concluzii şi propuneri}

Se consideră a fi acesta începutul sfârşitului secretului bancar, aşa cum susţin autorităţile europene? Va deveni sceretul bancar, definit în 
prezent ca fiind nelimitat, necondiționat şi izolat, o instituție flexibilă, transparentă şi echilibrată? Şi dacă da, secretul bancar va trebui să respecte, fiindcă se află dintotdeauna pe linia fragilă dintre drepturi şi obligații, libertatea dreptului la informații versus dreptul la protecția datelor cu caracter personal. Ce schimbă total acest raport este reprezentat de nevoia de lichidităţi, perpetuarea inegalității, a distribuției dezechilibrate, lipsa echilibrului dintre interesul public şi interesul individual, ineficiența supravegherii activității bancare, adică exact premisele de la care am început studiul de faţă. De aceea vorbim doar de un început, timid, al sfârşitului secretului bancar, fiindcă la cele de mai sus se adaugă şi:

- Acutizarea problemelor sociale, respectiv discrepanțele enorme

- Globalizarea fraudelor, respectiv insuficiența fondurilor publice destinate publicului

- Perfecționarea managementului metodelor de fraudare

- Constituirea unor rețele umane sofisticate de fraudare

- Scăderea capacităţii de guvernare concomitent cu întărirea continuă a locului băncilor în societate

- Intensificarea fără precedent a expunerii sociale prin abundența rețelelor electronice de socializare concomitent cu folosirea abuzivă a confidentialității în domenii sensibile, cum este cel bancar

- Tehnicizarea fără precedent a instrumentelor bancare ş.a.

Ca strategie de ansamblu, la nivel statal şi economic, încheierea de acorduri, o redistribuire echitabilă şi o diminuare a diferenţelor sociale ar constitui o soluție cu caracter general. În alte domenii, cum este cel social, se poate propune un obiectiv pe termen foarte lung, respectiv o diminuare a diferențelor sociale. În schimb, apariția aşa numitului "om nou, educat şi moral" pare o perspectivă de viitor din ce în ce mai indepărtată, cum se prefigurează, de altfel, şi atragerea elitelor în sfera guvernării.

\section{References}

Aubert, M. (1984). The Limit of Swiss Bank Secrecy under Domestic and International Law. Berkley Journal of International Law, 2(2), 273-297. Available online at:

http://scholarship.law.berkeley.edu/cgi/viewcontent.cgi?article $=102$ $\underline{0 \text { \&context }=\text { bjil }}$ 
Buciu, I .C. (2012). Secretul bancar prin prisma reglementării obligației de confidențialitate şi a obligației de neuz a băncii. Analele UVT Drept, 2014(1), 226-232.

Jurj - Tudoran, R., Şaguna, D. D. (2013). Spălarea banilor. Elemente de teorie și practică judiciară. Bucureşti: Ed. C.H.Beck.

Postolache, R. (2012). Drept bancar. București: Ed. C.H. Beck, (pp.78-79).

Silberstein, I., Bercea, L. (ed.), (2008). Probleme actuale în dreptul bancar/Current issues in banking law. Bucureşti: Ed. Wolters Kluwer, (pp.89-92).

Săuleanu, L., Smarandache, L., Dodocioiu, A. (2011). Drept bancar, Ediția a II a. Bucureşti: Ed. Universul Juridic, (pp.56-57)

*** (2014). Tendințe actuale in domeniul financiar bancar in legislatia natională, europeană si internatională/National, European and International Legal Developments in Financial and Banking Field. Bucureşti: Ed. Hamangiu.

\section{Biodata}

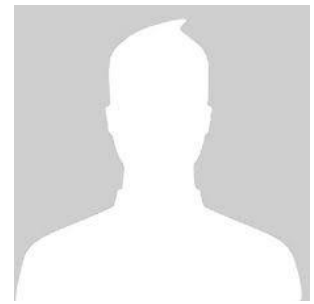

Gheorghe Carmen Adriana este cadru didactic la Universitatea Transilvania din Braşov din anul 1991. In prezent îşi desfăşoară activitatea în calitate de conferențiar la Facultatea de Drept a Univesităţii Transilvania din Braşov. A sustinut teza de doctorat $\mathrm{cu}$ titlul "Regimul juridic al societății comerciale bancare" în anul 2007 la Universitatea din Bucureşti, coordonator prof.univ.dr. St.D.Cărpenaru. A publicat lucrări de referință în domeniul dreptului bancar- Drept bancar, Editura C.H.Beck, Bucureşti, 2008, ed.I, Drept bancar, Editura C.H. Beck, Bucureşti, 2006, ed.II., Drept bancar, Editura C.H.Beck, Bucureşti, 2014, ed.III. 